\title{
ENRAIZAMENTO in vitro DE GENÓTIPOS DE GÉRBERA EM MEIO DE CULTURA ALTERNATIVO
}

COUTO, Tarcisio Rangel do ARAUJO, João Sebastião de Paula ${ }^{1}$ VICENTE, Michele Cagnin ${ }^{1}$ ALMEIDA, Leandro Miranda de ${ }^{1}$

\author{
Recebido em: 2020.03.01 \\ Aprovado em: 2020.04.29 \\ ISSUE DOI: $10.3738 / 1982.2278 .3744$
}

\begin{abstract}
RESUMO: O trabalho objetivou-se a otimizar a micropropagação de genótipos de gérbera promovendo o enraizamento in vitro em meio de cultura alternativo. Foram utilizados os genótipos 'Pacific', 'Igor', 'Igloo', 'Mephisto', GA, GL e GR. O experimento foi conduzido em delineamento inteiramente casualizado em esquema fatorial 7x2, sendo sete genótipos de gérbera e dois tipos de meio de cultura: MS e $B \& G^{\circledR}$ Orquídeas. Cada tratamento teve 10 repetições e a unidade experimental foi representada por um frasco com $50 \mathrm{~mL}$ de meio de cultura e 10 brotações. Utilizou-se o meio MS (Phytotecnology Laboratories ${ }^{\circledR}$ ), contendo $30 \mathrm{~g} . \mathrm{L}^{-1}$ de sacarose e adição de ágar $\left(7,5\right.$ g. $\left.\mathrm{L}^{-1}\right)$. O meio $\mathrm{B} \& \mathrm{G}^{\circledR}$ Orquídeas suprimento é um meio de cultura pronto para uso que contém sacarose e carvão ativado na sua composição. Para esse meio foi usando 8,0 g. $\mathrm{L}^{-1}$ de ágar. Após 30 dias de enraizamento in vitro foram avaliados a sobrevivência, número de folhas, número de brotações, número de raízes e massa da matéria fresca das mudas. Em geral, foi observado nos genótipos oriundos de meio de cultura $B \& G^{\circledR}$, as melhores repostas para as variáveis analisadas. $\mathrm{O}$ meio $\mathrm{B} \& \mathrm{G}^{\circledR}$ Orquídeas foi eficiente para promover o enraizamento in vitro de todos os genótipos avaliados de gérbera.
\end{abstract}

Palavras-chave: Crescimento. Cultivar. Gerbera jamesonii Bolus Ex. Hook. Micropropagação.

\section{In vitro ROOTING OF GERBERA GENOTYPES ON A ALTERNATIVE CULTURE MEDIUM}

\begin{abstract}
SUMMARY: The objective of this work was to optimize micropropagation of gerbera genotypes by promoting in vitro rooting on a alternative culture medium. The genotypes 'Pacific', 'Igor', 'Igloo', 'Mephisto', GA, GL and GR were used. The experiment was set up in a completely randomized design in factorial $7 \times 2$, with seven gerbera genotypes and two culture medium types: $M S$ and $B \& G^{\circledR}$ Orchids. Each treatment had 10 repetitions and the experimental unit was represented by one bottle with $50 \mathrm{~mL}$ culture medium and 10 shoots. MS medium (Phytotechnology Laboratories $\left.{ }^{\circledR}\right)$ containing sucrose $\left(30\right.$ g. $\left.\mathrm{L}^{-1}\right)$ and addition agar $\left(7,5 \mathrm{~g} . \mathrm{L}^{-1}\right)$ was used. B\&G ${ }^{\circledR}$ Orchid supply medium is a ready-to-use culture medium containing sucrose and activated charcoal in its composition. For this medium was using agar $\left(8,0\right.$ g. $\left.\mathrm{L}^{-1}\right)$. After 30 days in vitro rooting, survival, number of leaves, number of shoots, number of roots and mass of the fresh matter of the plant were evaluated. In general, the best responses for the analyzed variables were observed in the genotypes, from $B \& G^{\circledR}$ culture medium. The $B \& G^{\circledR}$ Orchids medium was efficient to promote in vitro rooting of all gerbera genotypes analyzed.
\end{abstract}

Keywords: Growth. Cultivar. Gerbera jamesonii Bolus Ex. Hook. Micropropagation.

\section{INTRODUÇÃO}

A gérbera (Gerbera jamesonii Bolus Ex. Hook) é uma planta herbácea, pertencente à família Asteraceae e originária da África do Sul (MANNING et al., 2016). As folhas têm formato em roseta e das gemas axilares na base do pecíolo de algumas delas evoluem os brotos florais que desenvolvem pedúnculos com inflorescência terminal em capítulo. Nos últimos anos, houve um

\footnotetext{
${ }^{1}$ Universidade Federal Rural do Rio de Janeiro. Instituto de Agronomia - Departamento de Fitotecnia - Laboratório de Cultura de Tecidos Vegetais.
} 
crescente interesse pelos tipos de corte, pois suas flores mostram boa durabilidade e uma variação de cores e formas que satisfaz os mercados mais exigentes (BENEMANN et al., 2014).

Existem dois métodos para a multiplicação da gérbera: sexual e vegetativo. Por ser uma planta de polinização cruzada, a propagação via semente não é muito interessante comercialmente, pelo fato de haver segregação na progênie o que torna a produção desta pouco interessante dada à variabilidade das plantas produzidas. Por isso, o emprego da cultura de tecidos vegetais (micropropagação) tem sido crescente para essa espécie, tornando-se uma alternativa bastante viável para sua disseminação em larga escala (CARDOSO; SILVA, 2013).

Os laboratórios de propagação comercial de plantas in vitro (biofábricas) enfrentam grandes problemas com os altos custos da micropropagação de diferentes espécies vegetais de interesse econômico. Assim, o desenvolvimento de novas tecnologias que promovam a melhoria da técnica com a redução dos custos, é fundamental para o estabelecimento de protocolos de propagação que permitam uma agricultura moderna e sustentável (PUROHIT et al., 2011).

O meio de cultura pode otimizar o protocolo de micropropagação sendo um fator chave para o sucesso de uma cultura in vitro. Este meio é composto de substâncias essenciais para o crescimento dos tecidos, de acordo com requisitos de cada espécie, e é amplamente responsável para o padrão de desenvolvimento in vitro. Assim, o meio de cultura deve ser escolhido de acordo com o objetivo do estudo e as espécies trabalhadas (HUNHOFF et al., 2018). O meio de cultura mais comumente utilizado para micropropagação é os sais de MS (MURASHIGE; SKOOG, 1962), consistindo de sais inorgânicos, carboidratos, vitaminas com concentrações equilibradas de nutrientes para o desenvolvimento de plantas.

A regulação das condições ambientais, incluindo a intensidade luminosa, $\mathrm{CO}_{2}$, concentração de sacarose e nutrientes fornecidos durante o cultivo in vitro, podem melhorar o crescimento da planta de certas espécies quando são transferidas para condições ex vitro (aclimatização) (EL-HAWAZ et al., 2016). Como o crescimento de órgãos vegetais tem diferentes exigências nutricionais, o uso de meio MS para o crescimento/desenvolvimento in vitro, pode não ser o mais adequado para a uma espécie vegetal, como, por exemplo, a gérbera. Além disso, diferentes genótipos de plantas podem requerer nutrição in vitro específica para as diversas fases da micropropagação (NIEDZ et al., 2014).

O meio de cultura MS precisa de uma série de reagentes químicos em sua formulação, que geralmente são caros e difíceis de adquirir. Essa situação dificulta a produção de mudas, especialmente por agricultores que estão iniciando na atividade. Pesquisas indicam que uma maneira de simplificar a produção e reduzir os custos do meio de cultura é usar fertilizantes comerciais como base de nutrientes (UNEMOTO et al., 2007; SU et al., 2012; SCHNEIDER et 
al., 2014; PEDROSO-DE-MORAES et al., 2014; SILVA et al., 2015). Além disso, é possível adicionar compostos orgânicos para substituir ou suplementar os níveis de açúcar, vitaminas, aminoácidos e reguladores de crescimento em meio de cultura (VIEIRA et al., 2009), visando a produção em larga escala de diferentes cultivares de gérbera, que requerem condições de cultivo específicas.

Neste contexto, este trabalho teve por objetivo avaliar a otimização da micropropagação de genótipos de gérbera promovendo o enraizamento in vitro em meio de cultura alternativo em substituição ao meio MS.

\section{MATERIAL E MÉTODO}

O experimento foi realizado no Laboratório de Cultura de Tecidos Vegetais (LCTV) da Universidade Federal Rural do Rio de Janeiro (UFRRJ), localizada no município de Seropédica RJ. Os genótipos de gérbera utilizados foram oriundos de floricultores da região Serrada do estado do Rio de Janeiro. Dos sete genótipos obtidos, quatro foram identificadas como as cultivares 'Pacific', 'Igor', 'Igloo' e 'Mephisto'. Os demais, devido ao desconhecimento dos floricultores, foram identificados pela cor da flor como: "gérbera amarela - GA", "gérbera rosa" GR e "gérbera laranja - GL". Estes genótipos foram cultivados por três anos em casa de vegetação na UFRRJ antes do início da pesquisa de micropropagação.

$\mathrm{O}$ experimento foi instalado na fase de enraizamento in vitro. As brotações dos genótipos de gérbera foram oriundas da fase de multiplicação da micropropagação e estavam em quinto subcultivo (fase de multiplicação) em meio MS. O experimento foi conduzido em delineamento inteiramente casualizado em esquema fatorial 7x2, sendo sete genótipos de gérbera e dois tipos de meio de cultura: $\mathrm{MS}$ e $\mathrm{B} \& \mathrm{G}^{\circledR}$ Orquídeas. Cada tratamento teve 10 repetições e a unidade experimental foi representada por um frasco $(130$ x $90 \mathrm{~cm}) \mathrm{com} 50 \mathrm{~mL}$ de meio de cultura e 10 brotações.

Foi utilizado o meio MS (MURASHIGE; SKOOG, 1962) e as vitaminas de White (Phytotecnology Laboratories ${ }^{\circledR}$ ), contendo 30 g. $\mathrm{L}^{-1}$ de sacarose P.A. (Isofar ${ }^{\circledR}$ ), pH ajustado para 5,8 antes da adição de ágar $\left(7,5\right.$ g. $\mathrm{L}^{-1}$ de ágar Vetec $\left.{ }^{\circledR}\right)$ e posterior autoclavagem por 15 minutos a 1,0 atm. e $121^{\circ} \mathrm{C}$. O meio $B \& G^{\circledR}$ Orquídeas suprimento é um meio de cultura pronto para uso que contém sacarose e carvão ativado na sua composição. Para esse meio foi utilizado 8,0 g.L $\mathrm{L}^{-1}$ de ágar $\left(\right.$ Vetec $\left.^{\circledR}\right)$ e o pH foi ajustado para 5,8 e posterior autoclavagem por 15 minutos a 1,0 atm. e $121^{\circ} \mathrm{C}$.

As brotações foram transferidas para os meios de cultivo propostos, em seguida foram mantidas em sala de cultivo à temperatura de $26 \pm 2{ }^{\circ} \mathrm{C}$ e irradiância de $30 \mu \mathrm{mol} . \mathrm{m}^{-2} . \mathrm{s}^{-1}$, provida 
por lâmpadas fluorescentes $\left(\operatorname{OSRAM}^{\circledR}\right.$, semelhante à luz do dia) e fotoperíodo de 16:8 horas (luz: escuro). Após 30 dias de enraizamento in vitro, foram avaliados a porcentagem de sobrevivência e enraizamento, a massa da matéria fresca (MF), número de folhas (NF) e de raízes (NR) e o número de brotações (NB).

Os dados obtidos foram submetidos à análise de variância, averiguando-se a normalidade pelo teste de Lilliefors e a homogeneidade pelo teste Shapiro-Wilk. Não havendo restrições e quando verificada a significância nas interações ou nos fatores, foi aplicado o teste de média de Tukey, adotando-se 5\% de probabilidade. Utilizou-se o software Sisvar (FERREIRA, 2014) para as análises estatísticas e o programa Excel 2013 para elaboração dos gráficos.

\section{RESULTADO E DISCUSSÃO}

A porcentagem de sobrevivência das mudas de todos os genótipos foi alta (média de 98\%). A porcentagem de enraizamento de todos os genótipos nos tratamentos foi $100 \%$, sem diferença estatística entre os mesmos. A Tabela 1 mostra o resumo da ANOVA para o número de folhas (NF), número de raízes (NR), número de brotações (NB) e massa da matéria fresca (MF) das mudas dos sete genótipos de gérbera, obtidos após 30 dias de enraizamento in vitro em diferentes meios de cultura.

Observou-se que a variável NF foi significativa para o fator meio e a interação genótipo $\mathrm{x}$ meio. NR não apresentou resposta significativa. NB apontou resposta significativa para o fator genótipo e a interação genótipo x meio e a variável MF foi significativa para a interação genótipo $\mathrm{x}$ meio. A Figura 1 apresenta as diferença significativas para o fator meio da variável NF.

Tabela 1. Resumo da análise de variância para a número de folhas, número de raízes, número de brotações e massa da matéria fresca dos genótipos 'Pacific', 'Igloo', 'Igor', 'Mephisto', GA, GR e GL, após 30 dias de enraizamento in vitro.

\begin{tabular}{|c|c|c|c|c|c|}
\hline \multirow{2}{*}{$\begin{array}{l}\text { Fontes de } \\
\text { Variação }\end{array}$} & \multirow[t]{2}{*}{ GL } & \multicolumn{4}{|c|}{ Quadrado Médio } \\
\hline & & NF & NR & NB & MF \\
\hline Genótipo (GEN) & 6 & $1,607143^{\mathrm{ns}}$ & $3,345465^{\mathrm{ns}}$ & $2,595238^{*}$ & $0,165611^{\mathrm{ns}}$ \\
\hline Meio & 1 & $10,314286^{*}$ & $1,47007^{\mathrm{ns}}$ & $0,028571^{\mathrm{ns}}$ & $0,141694^{\mathrm{ns}}$ \\
\hline GEN x Meio & 6 & $2,830952^{*}$ & $1,845784^{\mathrm{ns}}$ & $1,328571^{*}$ & $0,263788^{*}$ \\
\hline Erro & 126 & 0,863492 & 1,093599 & 0,594628 & 0,099089 \\
\hline Total & 139 & & & & \\
\hline $\mathrm{CV}(\%)$ & & 17,72 & 23,54 & 108,01 & 50,88 \\
\hline Média Geral & & 5,24 & 4,37 & 0,7142 & 0,6202 \\
\hline
\end{tabular}


Figura 1. Número de folhas em mudas de sete genótipos de gérbera após 30 dias de enraizamento in vitro em diferentes meios de cultura.

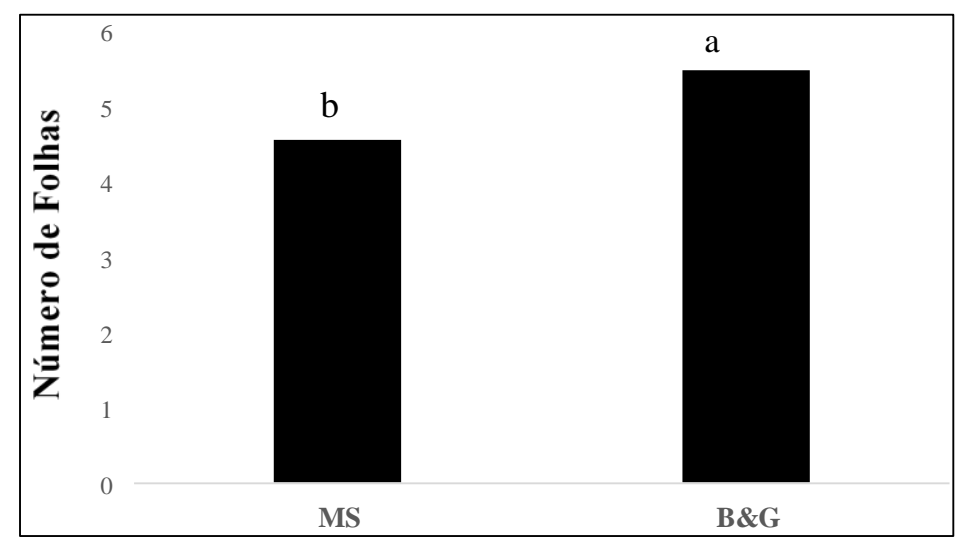

MS-Meio de cultura MS, B\&G-Meio de Cultura $B \& G^{\circledR}$. As letras diferem estatisticamente (Tukey, $p>0,05$ ).

A variável NF foi significativa e, apresentou média geral maior para mudas cultivadas em meio $B \& G^{\circledR}$ do que àquelas cultivadas em meio MS. Na Tabela 2 são apresentados os dados da interação genótipo x meio da variável NF.

Tabela 2. Interação genótipo x meio para o número de folhas obtidas após 30 dias de enraizamento in vitro dos sete genótipos de gérbera.

\begin{tabular}{cccccccc}
\hline Trat. & 'Pacific & 'Igloo' & 'Igor' & 'Mephisto' & GA & GR & GL \\
\hline $\mathrm{MS}$ & $4,8 \mathrm{bB}$ & $6,1 \mathrm{aA}$ & $5,5 \mathrm{aAB}$ & $4,8 \mathrm{bB}$ & $4,7 \mathrm{aB}$ & $4,5 \mathrm{bB}$ & $4,4 \mathrm{bB}$ \\
$\mathrm{B} \& \mathrm{G}^{\circledR}$ & $5,8 \mathrm{aA}$ & $5,5 \mathrm{aA}$ & $5,1 \mathrm{aA}$ & $5,7 \mathrm{aA}$ & $5,2 \mathrm{aA}$ & $5,7 \mathrm{aA}$ & $5,6 \mathrm{aA}$
\end{tabular}

Trat. - Tratamentos; MS - Meio de cultura MS; B\&G - Meio de Cultura $B \& G^{\circledR}$. Médias seguidas por uma mesma letra minúscula, em cada coluna e maiúscula, em cada linha, não diferem estatisticamente (Tukey, p > 0,05).

Conforme a Tabela 2, os sete genótipos de gérbera avaliados tiveram número de folhas igual ou superior quando foram enraizados in vitro em meio de cultura $B \& G^{\circledR}$ em relação ao meio MS.

Observou-se que o NF obtidas no tratamento com $B \& G^{\circledR}$ foram superiores aos encontrados nos trabalhos de Kumari et al. (2018) e Vijayalakshmi et al. (2019), quando esses autores utilizaram o meio MS com 30 g. $\mathrm{L}^{-1}$ de sacarose na fase de enraizamento de cultivares de gérbera. Pode-se destacar ainda que a média do número de folhas das mudas enraizadas em $B \& G^{\circledR}$ foram superiores quando comparado ao enraizamento da gérbera 'Dura' em meio MS com 30 g.L $\mathrm{L}^{-1}$ de sacarose (PAWŁOWSKA et al., 2018).

Não houve diferença significativa entre os genótipos para NR devido à alta porcentagem de enraizamento dos mesmos. Outros autores também verificaram alta porcentagem de 
enraizamento em diferentes cultivares de gérbera nesta fase do cultivo in vitro (SHYLAJA et al., 2014; PAWŁOWSKA et al., 2018; KUMARI et al., 2018; VIJAYALAKSHMI et al., 2019).

Winarto; Yufdy (2017) testaram diferentes composições de meio MS no enraizamento in vitro da gérbera 'Black Jack'. Os autores perceberam maior taxa de enraizamento e crescimento das plantas em meio MS completo, suplementado com 30 g.L $\mathrm{L}^{-1}$ de sacarose e 1,5 g.L $\mathrm{L}^{-1}$ de carvão ativado.

A alta porcentagem de enraizamento observada nesta fase pode estar relacionada ao efeito positivo da auxina remanescente oriunda da fase de multiplicação in vitro. Mesmo não sendo adicionada auxina sintética (fitorregulador), a quantidade de auxina endógena presente nas brotações foi suficiente para iniciar a expansão da raiz e promover o estabelecimento do sistema radicular na fase de enraizamento in vitro (NAZ et al., 2012).

Para a variável NB observa-se que houve diferença significativa para os fatores genótipo (Figura 2) e a interação genótipo x meio (Tabela 3). Para ambos os meios de cultura, constatou-se que o genótipo GR foi estatisticamente igual a 'Mephisto', GA e GL para número de brotações e superior a 'Pacific', 'Igloo' e 'Igor'.

Figura 2. Número de brotações de mudas de sete genótipos de gérbera após 30 dias de enraizamento in vitro em diferentes meios de cultura.

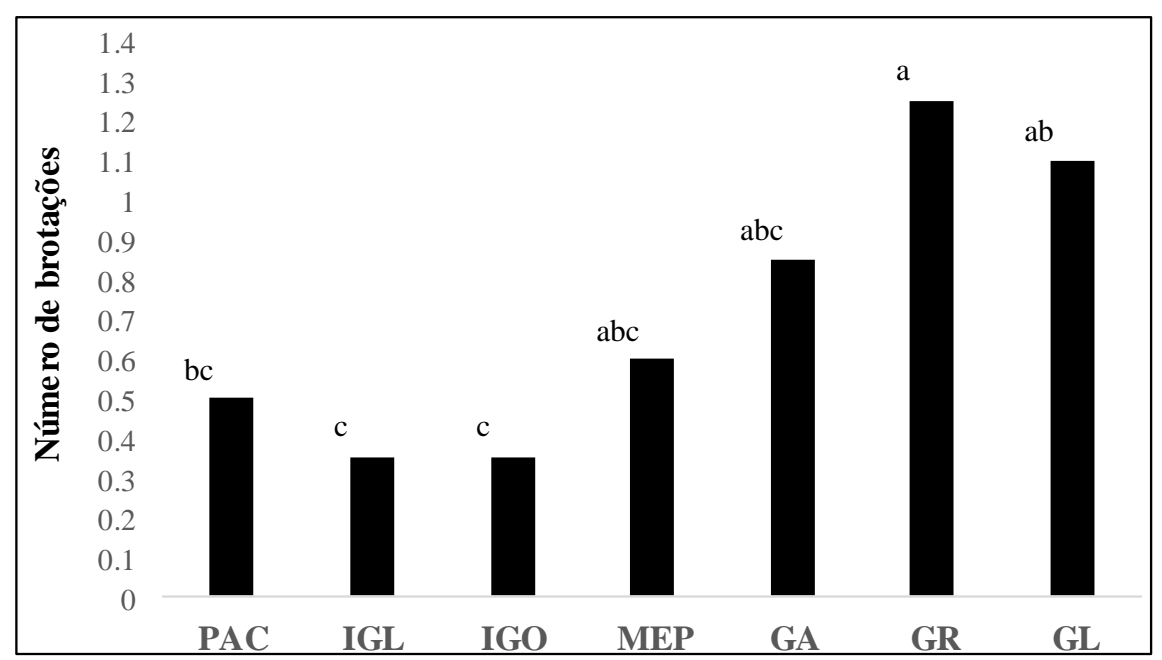

PAC - 'Pacific'; IGL - 'Igloo'; IGO - 'Igor'; MEP - 'Mephisto'; GA - gérbera amarela; GR - gérbera rosa; GL gérbera laranja. As letras diferem estatisticamente (Tukey, $\mathrm{p}>0,05$ ).

Na interação (Tabela 3), GR mostrou-se como o único genótipo que apresentou maior número de brotações, quando cultivado em meio de cultura $B \& G^{\circledR}$. Os demais genótipos não apresentaram diferença significativa entre os meios de cultura para a variável NB.

Analisando-se dentro de cada meio de cultura, verificou-se que em meio MS os genótipos GA, GR e GL foram estatisticamente iguais e superiores a 'Pacific', 'Igloo', 'Igor', 'Mephisto' para NB. Quanto ao meio B\&G ${ }^{\circledR}$, os genótipos não apresentaram diferença significativa. 
Tabela 3. Interação genótipo x meio para a número de brotações obtidas após 30 dias de enraizamento in vitro dos sete genótipos de gérbera.

\begin{tabular}{cccccccc}
\hline Trat. & 'Pacific & 'Igloo' & 'Igor' & 'Mephisto' & GA & GR & GL \\
\hline $\mathrm{MS}$ & $0,4 \mathrm{aB}$ & $0,2 \mathrm{aB}$ & $0,2 \mathrm{aB}$ & $0,5 \mathrm{aB}$ & $1,0 \mathrm{aAB}$ & $1,8 \mathrm{aA}$ & $1,0 \mathrm{aAB}$ \\
${\mathrm{B} \& \mathrm{G}^{\circledR}}^{\circledR}$ & $0,6 \mathrm{aA}$ & $0,5 \mathrm{aA}$ & $0,5 \mathrm{aA}$ & $0,7 \mathrm{aA}$ & $0,7 \mathrm{aA}$ & $0,7 \mathrm{bA}$ & $1,2 \mathrm{aA}$
\end{tabular}

Trat. - Tratamentos; MS - Meio de cultura MS, B\&G - Meio de Cultura B\&G ${ }^{\circledR}$. Médias seguidas por uma mesma letra minúscula, em cada coluna e maiúscula, em cada linha, não diferem estatisticamente (Tukey, $p>0,05$ ).

Os resultados deste experimento corroboram com os dados encontrados por Shabanpour et al. (2011), para as variáveis NF, NR e NB. Os autores também utilizaram o meio MS com 30 g.L ${ }^{1}$ de sacarose na fase de enraizamento de dois genótipos de gérbera. Destaca-se que o meio de cultura $B \& G^{\circledR}$ apresentou resultado semelhante aos encontrados pelos autores para as variáveis citadas. Com relação a variável MF, observou-se diferença significativa para a interação genótipo $\mathrm{x}$ meio (Tabela 4).

Tabela 4. Interação genótipo x meio para massa da matéria fresca (g) obtida após 30 dias de enraizamento in vitro dos sete genótipos de gérbera.

\begin{tabular}{cccccccc}
\hline Trat. & 'Pacific & 'Igloo' & 'Igor' & 'Mephisto' & GA & GR & GL \\
\hline $\mathrm{MS}$ & $0,582 \mathrm{aAB}$ & $0,404 \mathrm{aB}$ & $0,393 \mathrm{aB}$ & $0,582 \mathrm{aAB}$ & $0,863 \mathrm{aA}$ & $0,731 \mathrm{aAB}$ & $0,562 \mathrm{bAB}$ \\
${\mathrm{B} \& \mathrm{G}^{\circledR}}^{\circledR}$ & $0,683 \mathrm{aA}$ & $0,654 \mathrm{aA}$ & $0,630 \mathrm{aA}$ & $0,510 \mathrm{aA}$ & $0,560 \mathrm{bA}$ & $0,648 \mathrm{aA}$ & $0,891 \mathrm{aA}$
\end{tabular}

Trat. - Tratamentos; MS - Meio de cultura MS; B\&G - Meio de Cultura $B \& G^{\circledast}$. Médias seguidas por uma mesma letra minúscula, em cada coluna e maiúscula, em cada linha, não diferem estatisticamente (Tukey, p > 0,05).

De acordo com a Tabela 4, as respostas foram diferentes entre os genótipos dentro de cada meio. Para o meio $B \& G^{\circledR}$, os genótipos não tiveram diferença estatística. Para o meio MS, as mudas do genótipo GA apresentaram MF estatisticamente igual a 'Pacific', 'Mephisto', GR e GL e superior aos demais.

Ao se analisar cada genótipo, observou-se que apenas os genótipos GA e GL apresentaram diferença significativa entre os meios de cultura. As mudas de GA acumularam mais biomassa quando cultivadas in vitro em meio MS, enquanto GL em meio B\&G ${ }^{\circledR}$.

Como já descrito anteriormente, o meio $B \& G^{\circledR}$ Orquídeas suprimento contém em sua formulação, além dos macros e micronutrientes, 1 g.L $\mathrm{L}^{-1}$ de carvão ativado e 40 g.L $\mathrm{L}^{-1}$ de sacarose. O meio MS utilizado nesta pesquisa continha 30 g.L.-1 de sacarose em sua composição, que é a concentração mais utilizada nas pesquisas com cultura de tecidos vegetais. A presença do carvão ativado e da maior concentração de sacarose pode ter proporcionado o maior crescimento/desenvolvimento in vitro dos genótipos de gérbera, como foi observado.

A sacarose é o açúcar mais utilizado no cultivo in vitro de plantas. Os efeitos positivos da sacarose sobre o crescimento de explantes em condições in vitro estão ligados à alta solubilidade 
na água, sua neutralidade elétrica e pela falta de um efeito inibidor na maioria dos processos bioquímicos. A sacarose ainda fornece uma fonte equilibrada de carbono para o crescimento celular com a liberação de hexoses que podem participar diretamente das vias glicolítica e das pentoses-fosfato (PUROHIT et al., 2011). Além disso, suporta o crescimento de células vegetais em cultura in vitro (FARIA et al., 2004). Muitos estudos demonstraram que açúcares solúveis em meio são geralmente adicionados em concentrações entre 10 e 30 g.L $\mathrm{L}^{-1}$ de glicose, frutose ou sacarose (KONÉ et al., 2015).

Geralmente, usando $30 \mathrm{~g} . \mathrm{L}^{-1}$ de sacarose no meio, de acordo com as recomendações de Murashige; Skoog (1962), resulta em um ótimo desempenho. Concentrações mais altas de sacarose adicionadas ao meio de cultura podem ter um efeito inibitório na absorção de nutrientes, diminuindo o potencial hídrico do meio, e induzindo o estresse osmótico (CARDOSO et al., 2013). No entanto, outros resultados mostraram que o aumento da concentração de sacarose no meio pode levar ao aumento do número de brotos e raízes (KONÉ et al., 2015). Em seus estudos, Koné et al. (2015) relataram que as concentrações de 40, 50 e 60 g.L $\mathrm{L}^{-1}$ de sacarose aumentaram a altura da planta, o número de folhas, o comprimento da raiz e a massa da matéria fresca do feijãobambara a uma taxa similar quando comparados ao controle $\left(30 \mathrm{~g} . \mathrm{L}^{-1}\right)$. Em outro estudo, o meio suplementado com 60 g. $\mathrm{L}^{-1}$ de sacarose foi o mais eficiente para aumentar a altura e a massa da matéria fresca de Dendrobium nobile cultivada in vitro (FARIA et al., 2004).

Pinheiro et al. (2018), com intuito de elevar as taxas de sobrevivência durante a etapa de aclimatização e posterior plantio a campo, avaliaram o enraizamento in vitro de bananeira cv. Pacovan, em diferentes concentrações de sais MS e de sacarose. Assim, sugeriram a utilização de meio MS com 50\% de sais (macro e micronutrientes), e redução ou manutenção de sacarose (15 ou 30 g. $\mathrm{L}^{-1}$ ) em 16h/35 dias de cultivo in vitro. Kadu (2013) também notaram maior taxa de enraizamento em meio MS suplementado com carvão ativado $\left(0,75\right.$ g.L $\left.{ }^{-1}\right)$.

A adição de carvão ativado ao meio de cultura pode promover ou inibir o crescimento in vitro. Conforme a espécie e o tipo de tecido utilizado, pode apresentar efeitos benéficos ou prejudiciais, e esses efeitos podem estar atribuído à formação de ambiente escuro no meio. $\mathrm{O}$ carvão ativado no meio de cultura é uma prática comum em trabalhos de cultura de tecidos vegetais, especialmente por sua capacidade de adsorção a diversas substâncias (KADAM et al., 2018). A adição do carvão ativado influencia no alongamento das plantas, podendo ser atribuída à adsorção de substâncias inibitórias do meio ou adsorção de produtos tóxicos liberados pelos explantes que causam variação do $\mathrm{pH}$ do meio de cultura e o $\mathrm{pH}$ pode promover maior e melhor aproveitamento dos nutrientes (THOMAS, 2008). 
Os fatores que mais frequentemente determinam o sucesso da micropropagação são a origem do explante e o meio nutritivo onde são cultivados (FERREIRA et al., 2016). Alterações nas condições de cultivo nessa fase de enraizamento in vitro, visando à otimização do processo com a redução de gastos, seja pela diminuição do período, utilização de fertilizantes como meio de cultura e rustificação das mudas para sofrerem menos com a transferência para a aclimatização, foram feitas com êxito em várias espécies de plantas (UNEMOTO et al., 2007; CARDOSO et al., 2013; SILVA et al., 2015; KADAM et al., 2018; PINHEIRO et al., 2018).

A inclusão do meio $B \& G^{\circledR}$ Orquídeas suprimento na fase de enraizamento in vitro de diferentes genótipos de gérbera foi uma tentativa de otimizar o crescimento/enraizamento das mudas neste estádio da micropropagação. Segundo Pawłowska et al. (2018), essas modificações visam principalmente a redução ou o incremento de alguns componentes que podem promover melhor crescimento em tecidos de gérberas.

Santos et al. (2017) avaliaram o crescimento in vitro de Dendrobium phalaenopsis "Madame Pompadour" no meio de cultivo MS e em dois meios a base dos fertilizantes comerciais. Assim, constataram que o meio de cultura à base de fertilizante foi superior para as variáveis número de folhas, número de raízes e massa da matéria fresca.

Favetta et al. (2014) estudaram o efeito de fertilizantes comerciais e a adição da polpa de banana no desenvolvimento in vitro de plântulas de Vanda tricolor. Os autores concluíram que foi possível utilizar o meio simplificado à base de fertilizante Biofert ${ }^{\circledR}$ acrescido de polpa de banana em substituição ao meio MS para o desenvolvimento in vitro de $V$. tricolor.

Pedroso-de-Moraes et al. (2014) avaliaram a conversão de ápices radiculares de da orquídea Catasetum rooseveltianum. Constataram maior taxa de regeneração e enraizamento das brotações em meio B\&G ${ }^{\circledR}$ Orquídeas acrescido de $200 \mathrm{~mL} \cdot \mathrm{L}^{-1}$ de água de coco.

Schneider et al. (2014) testaram diferentes tipos de meio de cultura para germinação e formação de protocórmio das orquídeas Cattleya intermedia e Cattleya warneri. Os autores concluíram que para germinação das sementes, os melhores meios foram MS e B\&G ${ }^{\circledR}$ em ambas orquídeas e para formação e crescimento in vitro dos protocórmios os melhores meios foram Kristalon Laranja ${ }^{\circledR}$ e $B \& G^{\circledR}$, também em ambas orquídeas.

Silva et al. (2015) testaram a germinação e crescimento in vitro da orquídea Arundina bambusifolia em diferentes meios. Assim, verificaram que o fertilizante $B \& G^{\circledR}$ suplementado com 30 g.L $\mathrm{L}^{-1}$ de sacarose +200 mL.L $\mathrm{L}^{-1}$ de água de coco +2 g. $\mathrm{L}^{-1}$ de carvão ativado proporcionou a maior taxa de germinação, crescimento e enraizamento in vitro das mudas.

Apesar do meio $B \& G^{\circledR}$ ter sido elaborado para melhorar a nutrição de plantas de orquídeas in vitro, pode-se constatar que o mesmo também foi eficiente no enraizamento in vitro 
dos sete genótipos de gérbera desse estudo (Figura 3). Não foi encontrado na literatura trabalhos com o uso desse meio para o cultivo in vitro de plantas de gérberas.

Figura 3. Mudas dos genótipos de gérbera após 30 dias de enraizamento in vitro em meio MS e $\mathrm{B} \& \mathrm{G}^{\circledR}$ Orquídeas suprimento.

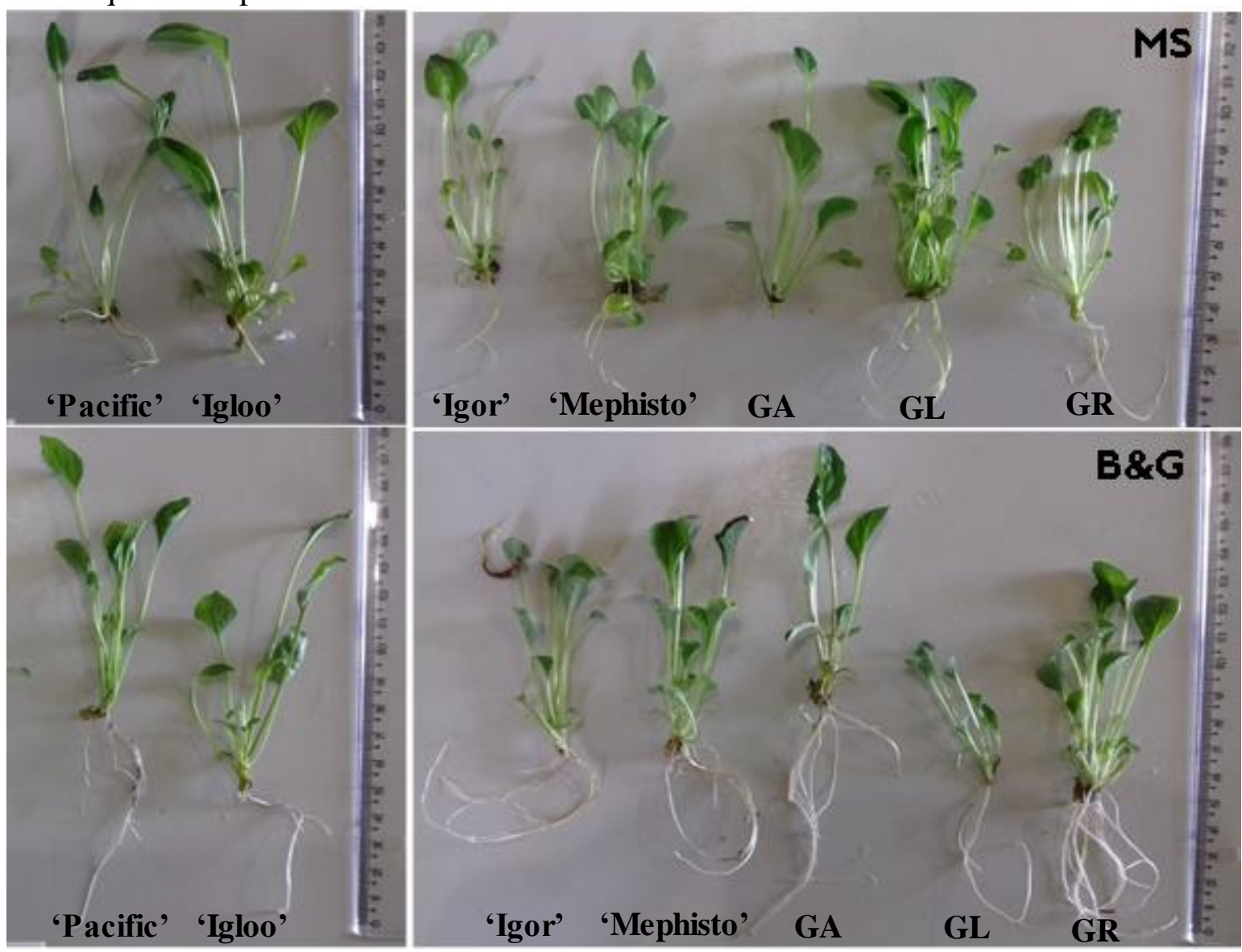

Fonte: Arquivo Pessoal

As mudas dos genótipos de gérbera oriundas dos dois meios de cultura foram aclimatizadas em casa de vegetação. Nesta condição apresentaram mais de $90 \%$ de sobrevivência após 90 dias, sem diferença estatística entre as mesmas.

Planejando a redução de custos na micropropagação dos genótipos estudados, trabalhos futuros testarão diferentes concentrações de sacarose, para se verificar a influência da mesma no desenvolvimento in vitro e na aclimatização das mudas, bem como analisar outros meios de cultura/fertilizantes em substituição ao meio MS nas fases de multiplicação e enraizamento in vitro. 


\section{CONCLUSÃO}

O meio de cultura $B \& G^{\circledR}$ Orquídeas suprimento apresentou-se como uma boa alternativa a utilização do MS suplementado com 30 g. $\mathrm{L}^{-1}$ de sacarose, visando o enraizamento in vitro dos genótipos de gérbera ('Pacific', 'Igloo', 'Igor', 'Mephisto', GA, GL e GR).

\section{AGRADECIMENTOS}

À Universidade Federal Rural do Rio de Janeiro (UFRRJ) e ao Curso de Pós-Graduação em Fitotecnia. À Universidade Federal Fluminense (UFF) e aos floricultores que doaram as gérberas para a realização da pesquisa de doutorado do primeiro autor.

\section{REFERÊNCIAS}

BENEMANN, D. P.; ARGE, L. W. P.; BARROS, W. S.; SEGEREN, M. I.; BIANCHI, V. J.; PETERS, J. A. Estimation of genetic variability of a Gerbera Brazilian collection based on morphological traits and EST-SSR markers. Australian Journal of Crop Science, v. 8, n. 5, p. 722-729, 2014.

CARDOSO, J. C.; ROSSI, M. L.; ROSALEMC, I. B.; SILVA, J. A. T. Pre-acclimatization in the greenhouse: An alternative to optimizing the micropropagation of gerbera. Scientia Horticulturae, v. 164, p. 616-624, 2013.

CARDOSO, J. C.; SILVA, J. A. T. Gerbera micropropagation. Biotechnology Advances, v. 1, n. 1, p. 1-14, 2013.

EL-HAWAZ, R.; PARK, D.; BRIDGES, W. C.; ADELBERG, J. Optimizing in vitro mineral nutrition and plant density increases greenhouse growth of Curcuma longa L. during acclimatization. Plant Cell, Tissue and Organ Culture, v. 126, n. 1, p. 33-42, 2016.

FARIA, R. T.; RODRIGUES, F. N.; REGO, L. D. V.; MULLER, C. In vitro Dendrobium nobile plant growth and rooting in different sucrose concentrations. Horticultura Brasileira, v. 22, n. 4, p. 780-783, 2004.

FAVETTA, V.; COLOMBO, R. C.; FARIA, R. T. Cultivo in vitro de Vanda tricolor Lindl. em meios de cultura simplificados. Revista Ciências Agrárias, v. 57, n. 2, p. 114-117, 2014.

FERREIRA, D. F. Sisvar: a guide for its bootstrap procedures in multiple comparisons. Ciência e Agrotecnologia, v. 38, n. 2, p. 109-112, 2014.

FERREIRA, L. T.; REAL, N. C.; PEREIRA, J. A. F.; ULISSES, C.; WILLADINO, L. Germinação in vitro de gongora (Orchidaceae) em meios nutritivos simplificados. Plant Cell Culture \& Micropropagation, v. 12, n. 1, p. 20-26, 2016.

HUNHOFF, V. L.; LAGE, L. A.; PALÚ, E. G.; KRAUSE, W.; SILVA, C. A. Nutritional requirements for germination and in vitro development of three Orchidaceceae species in the southern Brazilian Amazon. Ornamental Horticulture, v. 24, n. 1, p. 87-94, 2018. 
KADAM, D. D.; CHHATRE, A. A.; LAVALE, S. A.; SHINDE, N. A. Low-Cost alternatives for conventional tissue culture media. International Journal of Current Microbiology and Applied Sciences, v. 7, n. 4, p. 2523-2529, 2018.

KADU, A. R. In vitro micropropagation of gerbera using auxillary bud. Asian Journal of Bio Science, v. 8, n. 1, p. 15-18, 2013.

KONÉ, M.; KONÉ, T.; SILUÉ, N.; SOUMAHORO, A. B.; KOUAKOU, T. H. In vitro seeds germination and seedling growth of Bambara Groundnut (Vigna subterranea (L.) Verdc.

(Fabaceae)). Hindawi Publishing Corporation, the Scientific World Journal, v. 2015, p. 1-8, 2015.

KUMARI, S.; KUMAR, A.P.; SARKHEL, S.; SINGH, P.; KUMAR, R. Standardization of in vitro mass multiplication protocol for gerbera cv. Partrizia. International Journal of Current Microbiology and Applied Sciences, v. 7, n. 4, p. 514-519, 2018.

MANNING, J. C.; SIMKA, B.; BOATWRIGHT, J. S.; MAGEE, A. R. A revised taxonomy of Gerbera sect. Gerbera (Asteraceae: Mutisieae). South African Journal of Botany, v. 104, p. 142-157, 2016.

MURASHIGE, T.; SKOOG, F. A revised medium for rapid growth and bioassay with tobacco tissue cultures. Physiologia Plantarum, v. 15, n. 1, p. 473-497, 1962.

NAZ, S.; NAZ, F.; TARIQ, A.; ASLAM, F.; ALI, A.; ATHAR, M. Effect of different explants on in vitro propagation of gerbera (Gerbera jamesonii). African Journal of Biotechnology, v. 11, n. 37, p. 9048-9053, 2012.

NIEDZ, R. P.; HYNDMAN, S. E.; EVENS, T. J.; WEATHERSBEE, A. A. Mineral nutrition and in vitro growth of Gerbera hybrida (Asteraceae). In Vitro Cellular \& Developmental Biology Plant, v. 50, n. 4, p. 458-470, 2014.

PAWŁOWSKA, B.; ŻUPNIK, M.; SZEWCZYK-TARANEK, B.; CIOĆ1, M. Impact of LED light sources on morphogenesis and levels of photosynthetic pigments in Gerbera jamesonii grown in vitro. Horticulture, Environment, and Biotechnology, Gyeongsan, v. 59, n. 1, p. 115$123,2018$.

PEDROSO-DE-MORAES, C.; PETINI-BENELLI, A.; GÓMEZ, J. F. Ocorrência da conversão de ápices radiculares de Catasetum rooseveltianum Hoehne (Orchidaceae) em plântulas em meio de cultivo comercial. Orquidário, v. 28, n. 2, p. 58-63, 2014.

PINHEIRO, M. V. M.; CARVALHO, A. C. P. P; MARTINS, F. B. Modificações no meio de cultura, fotoperíodo e tempo de cultivo afetam o alongamento e enraizamento in vitro de bananeira cv. Pacovan. Nativa, v. 6, n. 1, p. 27-32, 2018.

PUROHIT, S. D.; TEIXEIRA, J. A. S.; HABIBI, N. Current approaches for cheaperand better micropropagation technologies. International Journal of Plant Developmental Biology, v. 5, p. $1-36,2011$. 
SANTOS, L. O. G; GIANINI, P. F.; PEDROSO-DE-MORAES, C. Crescimento in vitro de Dendrobium phalaenopsis c.v. "Madame Pompa Dour" cultivadas em diferentes meios de cultura e níveis de pH. Revista em Agronegócio e Meio Ambiente, v. 10, n. 1, p. 213-226, 2017.

SCHNEIDER, L.; ARAUJO, J. S. P.; ZAFFARI, G. R. Seed germination of Cattleya intermedia and Cattleya warneri in alternative culture media. American International Journal of Contemporary Research, v. 4, n. 7, p. 60-66, 2014.

SHABANPOUR, K.; SHARIFI, A.; BAGHERI, A.; MOSHTAGHI, N. Effect of genotypes and culture medium on shoot regeneration and proliferation of Gerbera jamesonii. African Journal of Biotechnology, v. 10, n. 57, p. 12211-12217, 2011.

SHYLAJA, M. R.; SASHNA, P.; CHINJUSHA, V.; NAZEEM, P. A. An efficient micropropagation protocol for Gerbera jamesonii bolus from flower buds. International Journal of Plant, Animal and Environmental Sciences, v. 4, n. 1, p. 641-643, 2014.

SILVA, K. A.; MELLO, V. S.; KARSBURG, I. V. Propagação in vitro de Arundina bambusifolia lindl. com diferentes potenciais hidrogenionicos. Enciclopédia Biosfera, v. 11, n. 22, p. 31-34, 2015 .

SU, M. J.; SCHNITZER, J. A.; FARIA, R. T. Polpa de banana e fertilizantes comerciais no cultivo in vitro de orquídea. Científica, v. 40, n. 1, p. 28-34, 2012.

THOMAS, T. D. The role of activated charcoal in plant tissue culture. Biotechnology Advances, v. 26, p. 618-631, 2008.

UNEMOTO, L. K.; FARIA, R. T.; VIEIRA, A. O. S.; DALIO, R. J. D. Propagação in vitro de orquídeas brasileiras em meio de cultura simplificado. Revista Brasileira de Agrociência, v. 13, n. 2, p. 267-269, 2007.

VIEIRA, J. G. Z.; UNEMOTO, L. K.; YAMAKAMI, J. K.; NAGASHIMA, G. T.; FARIA, R. T.; AGUIAR, R. S. Propagação in vitro e aclimatização de um híbrido de Cattleya Lindl.

(Orchidaceae) utilizando polpa de banana e água de coco. Científica, v. 37, n. 1, p. 48-52, 2009.

VIJAYALAKSHMI, C. L.; BABU, P.; BAGALI, A. N.; SOREGAON, C. D.; WADAGERI, A. H. In vitro regeneration studies in gerbera (Gerbera jamesonii Bolus). International Journal of Chemical Studies, v. 7, n.1, p. 1200-1205, 2019.

WINARTO, B.; YUFDY, M. P. Establishment of in vitro propagation protocol of Gerbera jamesonii Bolus ex Hook f.: explant and media selection to plantlet acclimatization. Journal of Agricultural Science, v. 28, n. 1, p. 1-9, 2017. 